\title{
Si-C films on alloys: characterization of ageing behavior in air
}

\author{
J.M. AGULLO, M. DUCARROIR, F. CLEMENDOT* and A. LINA* \\ IMP-CNRS, Université, 52 avenue de Villeneuve, 66860 Perpignan cedex, France \\ ${ }^{*}$ EDF-DER-EMA, Centre des Renardières, BP. 01, Ecuelles, 77250 Moret sur Loing, France
}

\begin{abstract}
Coatings of silicon rich silicon carbide are obtained in a plasma assisted device from tetramethylsilane and argon mixture, around $760 \mathrm{~K}$ under reduced pressure on metallicalloys: $\mathrm{FeCrAl}$ and NiCrAl.The atomic composition of the deposits is determined by microprobe analysis and adherence is evaluated by scratch test measurements. These results are discussed in relation with previous determinations obtained when identical films are deposited on low carbon steel substrates. All samples exhibit a similar behavior which denotes a good adherence. The formation of a diffusion zone is responsible for this trend.

The qualitative behavior of the coated substrate in air at high temperature $(1273 \mathrm{~K})$ is investigated in comparison with the uncoated substrate through cross section examinations by different analysis (EDS mapping, WDS profiles). The heat treatment $(10 \mathrm{~h}, 100 \mathrm{~h})$ induces a strong diffusion which is discussed. It is evidenced that the silicon carbide based films drastically change the oxidation mechanism (mainly in the case of $\mathrm{NiCrAl}$ ) and tend to improve the resistance of the substrate against an oxidizing atmosphere. Futhermore, some solutions to improve the lifetime of such metal/ceramic junctions are suggested. As for example, the interest of an alumina interlayer between $\mathrm{SiC}$ coating and $\mathrm{FeCrAl}$ substrate is experimentally shown.
\end{abstract}

Different alloys (Fe-based or Ni-based such as Kanthal or Inconel respectively) are used in electrical heating applications. In spite of containing chromium and aluminium, they are not resistant enough to oxidation in air. The idea of improving the oxidation resistance by an adequate protective ceramic coating is classical but needs, in every case, to be experimentally studied.

Among non oxide ceramics $\mathrm{SiC}$ is well known for its high temperature oxidation resistance due to the resulting $\mathrm{SiO}_{2}$ layer [1][2]. But $\mathrm{SiC}$ has a low coefficient of thermal expansion : when it coats a metallic substrate, the large resulting mismatch tends to cause thermal stresses which are detrimental.

Though this trend, some of us demonstrated that $\mathrm{SiC}$ based films which adhere well could be deposited on steel substrates [3].

The goal of the present work is to demonstrate the feasibility of the deposition of adherent coatings (around $10 \mu \mathrm{m}$ thick) and to study qualitatively their effect on oxidation protection of the substrates at higher temperature than that of deposition.

In this work, the layer deposition is carried out on Inconel $(60 \mathrm{wt} \% \mathrm{Ni}, 23 \mathrm{wt} \% \mathrm{Cr}, 14 \mathrm{wt} \% \mathrm{Fe}, 1.5$ wt $\% \mathrm{Al}$ ) and Kanthal $(72.7 \mathrm{wt} \% \mathrm{Fe}, 21.5 \mathrm{wt} \% \mathrm{Cr}, 5.8 \mathrm{wt} \% \mathrm{Al})$ by plasma assisted CVD (PACVD) between $850-900 \mathrm{~K}$. The technique allows a mean deposition rate of $40 \mu \mathrm{m}$ per hour, a fairly interesting value regarding an industrial surface treatment.

In the second step, oxidation tests at $1273 \mathrm{~K}$ are carried out in air for 10 and 100 hours. In order to maximize the life time of the specimens, the feasibility of diffusion barriers is demonstrated. 


\section{Coating elaboration and characterization}

The experimental device is a cold wall tubular reactor which enables development of a plasma assisted deposition from an input mixture of TMS (tetramethylsilane) and Argon (Figure 1). The glow discharge is generated by an induction coil connected to a R.F. generator working at $2 \mathrm{MHz}$. The grounded substrate is set backward in the coil; so, the temperature is depending upon its position (d) and input power (w). For fixed parameters $(\mathrm{d}, \mathrm{w})$, temperature is constant and measured by a thermocouple embedded in the substrate. Flow rates and pressure are accurately measured; the values are respectively $1300 \mathrm{~Pa}$ and $5 \mathrm{Nl} / \mathrm{h}$ with 10 percent of TMS. The substrate temperature varies slightly (between 750 and $800 \mathrm{~K}$ ) due to the lack of precision in position. From previous results on $35 \mathrm{CD} 4$ steel, such conditions must insure the most favourable deposit composition for adherence [3].

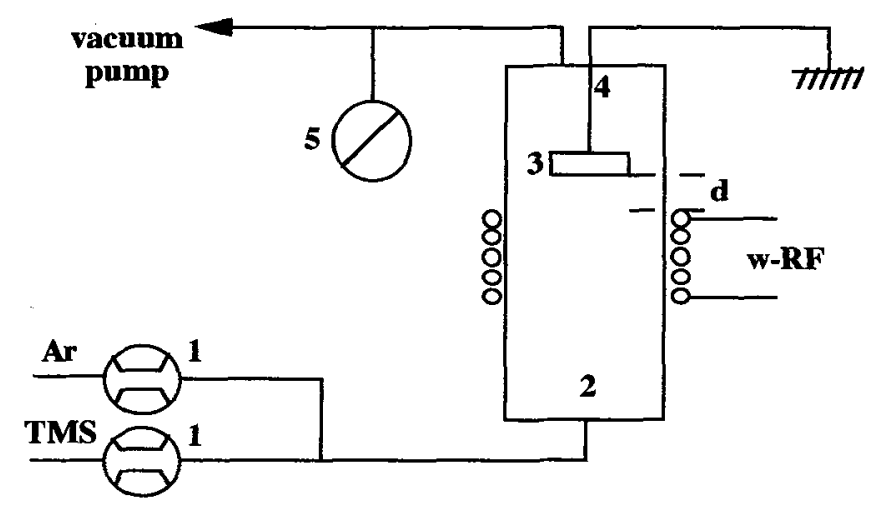

Figure 1 :PACVD apparatus - (1) massflowmeters (2) reactor (3) substrate (4) thermocouple (5) gauge (d) position (w) input power

A typical run consists of three steps : polishing the sample on diamond paste up to $1 \mu \mathrm{m}$ and cleaning it, then sputter etching in the reactor at the selected deposition temperature by a pure argon plasma for $10 \mathrm{~min}$ in order to remove the superficial Beilby layer and then deposition during $15 \mathrm{~min}$ from the reactive input gaseous mixture. The samples are cooled to room temperature in a pure argon atmosphere.

Scanning electron microscopy was used to examine the surface morphology and a Cameca electron microanalyser with wavelength dispersive spectrometers allowed to determine the atomic compositions of the coatings. Some charge effects lead to discrepancy in the results. This phenomenon is minimized by a light metallization and by comparison with a similar silicon carbide deposit well quantitatively analysed (PACVD sample on steel with $\mathrm{Si} / \mathrm{C}=1.2$ ). Adherence was evaluated by scratch test with acoustic emission under increasing load and compared with the afore mentioned reference sample. The deposit thickness was measured by a print ball technic. The coatings consist of a thick layer (from $8 \mu \mathrm{m}$ to $12 \mu \mathrm{m}$ ) with no apparent morphology on cross sections.

Figure 2 shows that the concentration depends on the sample position. Si concentration tends to increase with distance from the coil (that is a decrease in temperature). This variation confirms the trend previously evidenced on $35 \mathrm{CD} 4$ steel [3]. This phenomenon is related to the active species distribution caused by secondary reactions along the plasma : from experimental works of several authors, distance increases polymerized species with a higher silicon content [4][5]. The experimental data are not numerous enough to conclude on the real composition variation given in Figure 2 in function of distances. 

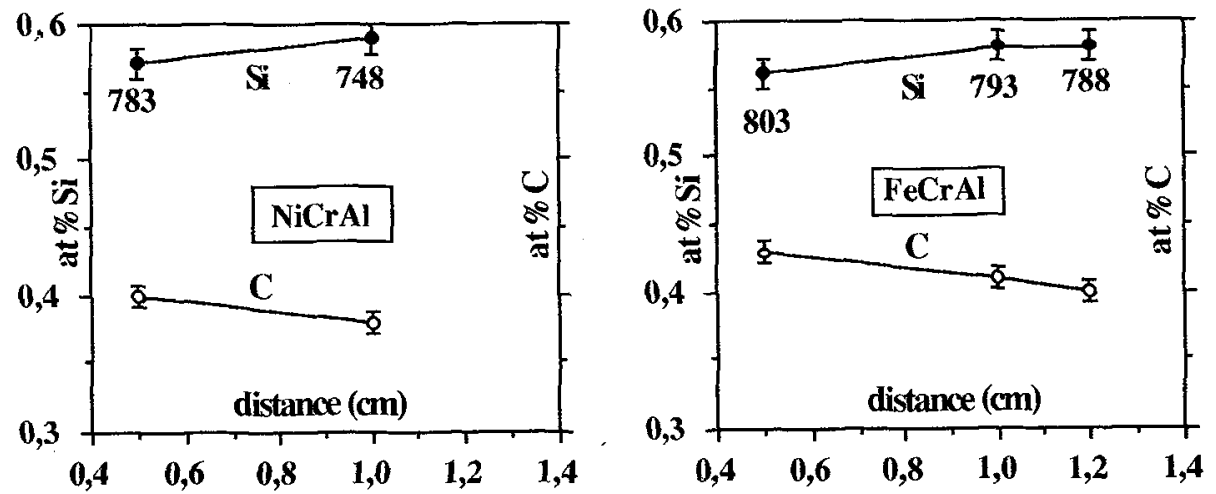

Figure 2 : atomic percent of elements in deposits vs distance between the coil and the substrate temperatures (Kelvin) are also reported.

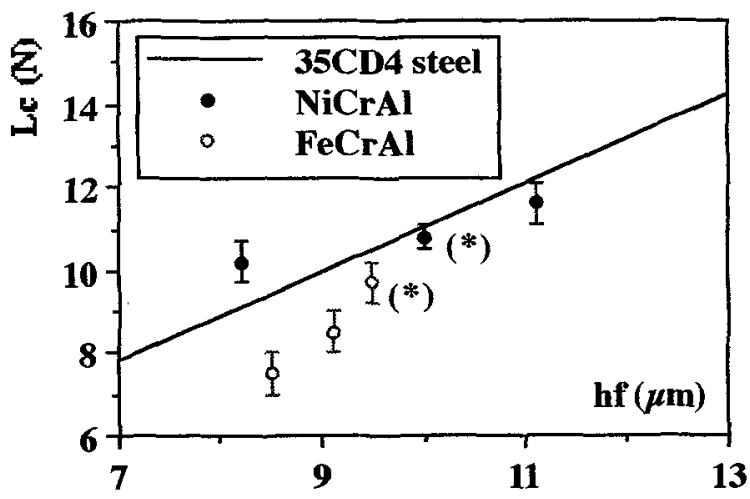

Figure 3 : scratch test critical loads vs thickness of the deposits in comparison with steel/SiC results : asterisks denote the samples choosen for oxidation experiments

Samples were scratched at a standard scratch speed of $0.17 \mathrm{~mm} / \mathrm{s}$. The simultaneous recording of an acoustic signal leads to the critical loads which are reported in Figure 3 versus deposit thickness and in regards to the experimental variation law obtained in [3] for deposits on $35 \mathrm{CD} 4$ steel : $L c(N)=0.32+1.07 \mathrm{~h} f(\mu \mathrm{m})$. The behavior of three types of samples is very similar, either in respect to both values and the scratch tracks. No difference appears in the failure damage : plastic deformation at the beginning is followed by cohesive failure inside the track and then adhesive failure with rather limited chipping and flaking.

Table 1 : some mechanichal properties for different alloys

\begin{tabular}{|c|c|c|}
\hline & $\begin{array}{c}\text { Vicker hardness } \\
(\mathrm{GPa})\end{array}$ & $\begin{array}{c}\text { thermal coefficient } \\
\text { of expansion } \\
\text { (ppm/K) }\end{array}$ \\
\hline 35CD4steel & 2.35 & 13.4 \\
\hline NiCrAl & 2.10 & 17.0 \\
\hline FeCrAl & 2.20 & 17.2 \\
\hline
\end{tabular}

As the hardness (own measurements) and thermal expansion coefficient (litterature and/or commercial data) of $35 \mathrm{CD} 4$ steel, FeCrAl, NiCrAl are quite identical (table 1) adhesion must be of the same order. However, comparison of the results show that adhesion on NiCrAl is the largest. Deadhesion is due to the total stored energy $(U)$ proportional to total stresses $\sigma^{2}$; where $\sigma$ is the sum of two terms: the residual 
thermal stresses and the stresses resulting from the applied load on the scratch tip. The first one is proportional to $\Delta \alpha \Delta \mathrm{T}$ (difference in thermal expansion coefficient between deposit and substrate-difference between deposit and room temperature). The second one is proportional to the scratch test critical load. So, for identical coatings prepared at constant temperature, for same critical loads, it comes out simply.

$$
U_{S i C / N i C r A l}=\frac{\Delta \alpha_{S i C / N i C r A l}^{2}}{\Delta \alpha_{S i C / 35 C D 4}^{2}} \quad U_{S i C / 35 C D 4} \# 2 U_{S i C / 35 C D 4}
$$

The slopes variations $\mathrm{Lc}=\mathrm{f}\left(\mathrm{h}_{\mathrm{f}}\right)$ could be attributed to differences in deposit-subtrate interactions. In spite of their low level, the Lc values correspond nevertheless to good adherence attributed to a thin diffusion layer consisting of iron or nickel silicides [6]. GDS profiles obtained from deposits either on FeCrAl or $\mathrm{NiCrAl}$ exhibit the same behavior of the emission intensities as a function of sputtering time. It is mainly seen that $\mathrm{Si}$ and $\mathrm{C}$ exist with $\mathrm{Fe}$ and $\mathrm{Ni}$. Under constant power with a voltage of $1000 \mathrm{~V}$, the recorded intensities vary from zero up to plateau values within a burning time of $48 \mathrm{~s}$. The differences (full intensity for $\mathrm{Ni}$ reached later-15 s- than for $\mathrm{Fe}$ ) are too slight to announce a real difference in a diffusion phenomenon. But, nevertheless, one can say that the thickness of the diffusion layer has probably a great influence on the interfacial strength. Schieppers [6] demonstrated that diffusion products between metals such as $\mathrm{Fe}$ or $\mathrm{Ni}$ and $\mathrm{SiC}$ are silicides and pure carbon. The only possible sequence is $\mathrm{SiC} / \mathrm{C} /$ silicides $/ \mathrm{metal}$ because carbon cannot migrate against its own activity gradient. Then carbon is always on the SiC side or enclosed in the metal silicides contiguous to $\mathrm{SiC}$. It is postulated that the failure suffered by diffusion bonding specimens ( $\mathrm{SiC} / \mathrm{Fe}$ ) originates from a thick brittle diffusion layer and the presence of pure carbon which has poor mechanical properties [7]. The phases obtained by several authors concerning different junctions are reported in table 2 .

Table 2 : experimentally found phases between amorphous $\mathrm{SiC}(*)$ or $\beta S i C$ and metals at different temperatures

\begin{tabular}{|c|c|c|c|}
\hline Couples & $\mathrm{T}(\mathrm{K})$ & Sequences & Ref. \\
\hline $\mathrm{Fe} / \mathrm{SiC}$ & 873 & $\mathrm{Fe} /(\mathrm{Fe}, \mathrm{Si})_{\alpha}+\mathrm{C} / \mathrm{SiC}$ & {$[3]$} \\
$\mathrm{Ni} / \mathrm{SiC}$ & 1123 & $\mathrm{Ni} / \mathrm{Ni}{ }_{3} \mathrm{Si} / \mathrm{Ni}_{5} \mathrm{Si}_{2} / \mathrm{Ni}{ }_{2} \mathrm{Si} / \mathrm{C} / \mathrm{SiC}$ & {$[6]$} \\
$\mathrm{Ni} / \mathrm{a}-\mathrm{SiC}(*)$ & 773 & $\mathrm{Ni} / \mathrm{Ni}_{3} / \mathrm{Si}_{12}+\mathrm{C} / \mathrm{Ni}_{2} \mathrm{Si}+\mathrm{C} / \mathrm{SiC}$ & {$[8]$} \\
$\mathrm{Ni} / \mathrm{SiC}$ & 1373 & $\mathrm{Ni} / \mathrm{Ni}_{3} \mathrm{Si}_{+}+\mathrm{C} / \mathrm{Ni}_{5} \mathrm{Si} i_{2}+\mathrm{C} / \mathrm{SiC}$ & {$[9]$} \\
$\mathrm{Ni} / \mathrm{SiC}$ & 1123 & $\mathrm{Ni} / \mathrm{Ni}_{3} \mathrm{Si} / \mathrm{Ni}_{5} \mathrm{Si}_{2}+\mathrm{C} / \mathrm{Ni}_{2} \mathrm{Si}+\mathrm{C} / \mathrm{SiC}$ & {$[10]$} \\
\hline
\end{tabular}

All these results are in agreement. Moreover in regards to the thermodynamic data, we can underline that nickel silicides are more stable than iron ones and the reaction diffusion layer is thicker [6]. Jackson's results [11] allowed determination of a function and description of the thickness of the diffusion layer in a junction $\mathrm{NiCrAl}(70$ at $\% \mathrm{Ni}, 20$ at\% $\mathrm{Cr}, 10$ at $\% \mathrm{Al}) / \mathrm{SiC}$ which is given by a classical law : $\mathrm{d}^{2}(\mu \mathrm{m})=2 . \mathrm{Kp}\left(\mu \mathrm{m}^{2} / \mathrm{h}\right) . \mathrm{t}(\mathrm{h}) . \mathrm{Kp}$ is thermally activated and its expression versus temperature is : $\operatorname{LnKp}\left(\mu \mathrm{m}^{2} / \mathrm{h}\right)=21.88-2.145 .10^{4} / \mathrm{T}(\mathrm{K})$. Then, the calculated diffusion layer thickness for a $\mathrm{NiCrAl} / \mathrm{SiC}$ junction treated at the deposition conditions $(15 \mathrm{~min}, 750 \mathrm{~K})$ is $250 \AA$.

\section{Oxidation behavior}

For oxidation study of the ceramic/metal couples, the samples marked in figure 3 were chosen $(10 \mu \mathrm{m}$ thick). Quantitative oxidation tests were carried out in air, in a tubular electric furnace, with a temperature rate of $7 \mathrm{~K} / \mathrm{min}$. After the tests, scanning electron microscope examinations and elemental analysis by line scan and/or by imaging were performed.

\section{- NiCrAl/SiC case}

SEM micrographs (figure 4) show the different aspects for uncoated and coated NiCrAl samples after an oxidation in air at $1273 \mathrm{~K}$ during 10 hours. The oxidation mechanism of uncoated $\mathrm{NiCrAl}$ presents some peculiarities : WDS analysis has shown that the $\mathrm{NiCrAl}$ coupon protects itself by a thin film enriched in chromium oxide (confirmed by the green color of the surface) with a rough interface with the underlying substrate; moreover oxygen combines also with aluminium to form alumina dendrites or islands extending inside the substrate, generally perpendicular to its surface. For oxidation times of 100 hours, alumina is detected over distances of a hundred micrometers from the initial surface. Then if longtime utilisation of $\mathrm{NiCrAl}$ in an oxidizing atmosphere is considered, this phenomenon will have to be suppressed. 

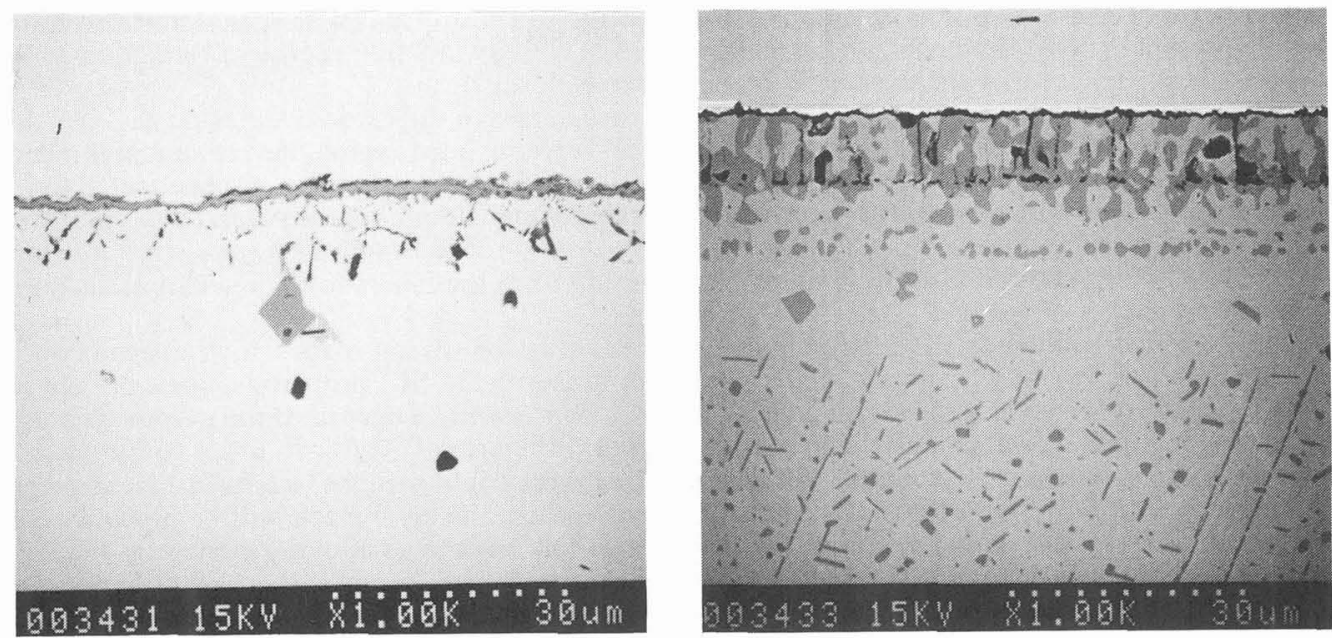

Figure 4 : cross sectionnal SEM micrographs of an uncoated NiCrAl (left) and a NiCrAl/SiC junction (right) after ageing in air at $1273 \mathrm{~K}$ for 10 hours

\begin{tabular}{|c|}
\hline Cr-O \\
\hline Ni-Si $(\mathrm{Cr})$ \\
\hline Al-O (Si,Ni) \\
\hline Substrate \\
\hline
\end{tabular}

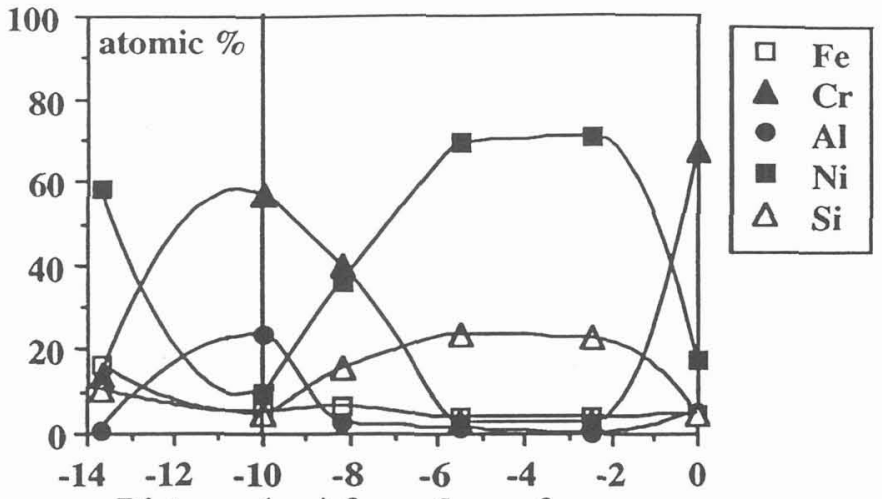

Distance $(\mu \mathrm{m})$ from the surface

Figure 5: (left) scheme of an EDS mapping after long oxidation in air $(1273 \mathrm{~K}, 100 \mathrm{~h})$ of $\mathrm{NiCrAl} / \mathrm{SiC}$ (right) cross sectional EDS profiles of a junction $\mathrm{NiCrAl} / \mathrm{SiC}(10 \mu \mathrm{m})$ after oxidation in air at $1273 \mathrm{~K}$ for 10 hours (0:outer surface)

Figure 5 shows the mean concentration profiles of metallic elements determined by EDS scans after short oxidation ( 10 hours) and represents the principal layers after long oxidation ( 100 hours). These layers were deduced from WDS mappings. Though it is completely reacted, the deposit changes the behavior against oxidation drastically. Aluminium seems to be fixed in a plane parallel to the free surface. The consumption of the ten micrometer $\mathrm{SiC}$ layer is in agreement with previous works : on the basis of Jackson's data (11), the thermal treatment at $1273 \mathrm{~K}$ during 10 hours of a diffusion couple $\mathrm{NiCrAl} / \mathrm{SiC}$ would lead to a $55 \mu \mathrm{m}$ thick diffusion layer.

To explain the layer sequence, chromium must diffuse outward. The sequence of phases and its evolution during time could be explained qualitatively as follows. At the beginning, no oxygen reaches the interface deposit substrate due to the protective coating. However, at that time, there is a strong chemical interaction at the inner interface by solid state diffusion reaction either:

$$
\begin{array}{ll} 
& x \mathrm{Si}+\mathrm{y} \mathrm{M} \rightarrow \mathrm{Si}_{\mathrm{x}} \mathrm{My}_{\mathrm{y}} \\
\text { or } \quad \mathrm{x}^{\prime} \mathrm{SiC}+\mathrm{y} \mathrm{M} \rightarrow \mathrm{Si}_{\mathrm{x}} \mathrm{M}_{\mathrm{y}}+\left(\mathrm{x}-\mathrm{x}^{\prime}\right) \mathrm{C}
\end{array}
$$


since in the ternary phase diagrams $\mathrm{Si}$ and/or $\mathrm{SiC}$ cannot be in equilibrium with nickel and chromium. Among the present metallic elements, nickel has the greatest activity and free energy of formation for the silicides; so, nickel silicides are the most probable phases to be formed.

As several authors demonstrated that nickel diffuses to form silicides in diffusion couples $\mathrm{Ni} / \mathrm{SiC}$ (6), such atomic mass transfer must leave, beneath the silicide zone, a Ni depleted region, that is an enrichment in chromium and aluminium in regards to the bulk substrate (figure 5). As a consequence, chemical activities are increased; then, chromium can diffuse outward more rapidly and aluminium be oxidized internally due to its very strong affinity with oxygen $\left(1300 \mathrm{~K}: \mathrm{Al}_{2} \mathrm{O}_{3}, \Delta \mathrm{Gf}=-1260 \mathrm{~kJ} / \mathrm{mol} ; \mathrm{Cr}_{2} \mathrm{O}_{3}, \Delta \mathrm{Gf}=-790 \mathrm{~kJ} / \mathrm{mol}\right.$ : $\mathrm{NiO}, \Delta \mathrm{Gf}=-94 \mathrm{~kJ} / \mathrm{mol}$ ), favored also by some cracks resulting from the inherent volume variations during the reaction.

The system is very complicated and the final pack must result in the silicon mass which depends on the silicon sink that is the coating thickness. If the goal is to preserve the $\mathrm{SiC}$ properties (for example low reactivity against oxygen and liquid aluminium), a diffusion barrier will be needed. If the purpose is only to change the oxidation behavior, mainly by avoiding internal formation of $\mathrm{Al}_{2} \mathrm{O}_{3}$ in order to increase for example the lifetime of heating elements, a siliconizing treatment could perhaps improve it. The reactivity will be of the same order as with $\mathrm{SiC}$ but in the absence of carbon, the layer stack will be probably more dense as no voids take place by gas evolution. As a matter of fact, silicon as alloying element is known to increase the oxidation behavior of M-Cr alloys (14). On the other hand, different authors describe solutions with copper [6] or titanium nitride [13] as interlayers between metals and SiC. Up to date, investigations are required to examine the potential of those solutions.

\section{- FeCrAl/SiC case}

Observations (figure 6) and analysis (figure 7) were carried out for the $\mathrm{SiC} / \mathrm{FeCrAl}$ junction. It is well known that FeCrAl alloys present a rather good resistance against oxidation due to the formation of a protective $\mathrm{Al}_{2} \mathrm{O}_{3}$ scale whose structure is dependant on the alloy compositions, but there is an increase trend to local scaling [14]. So, it is useful to look for a protective coating.
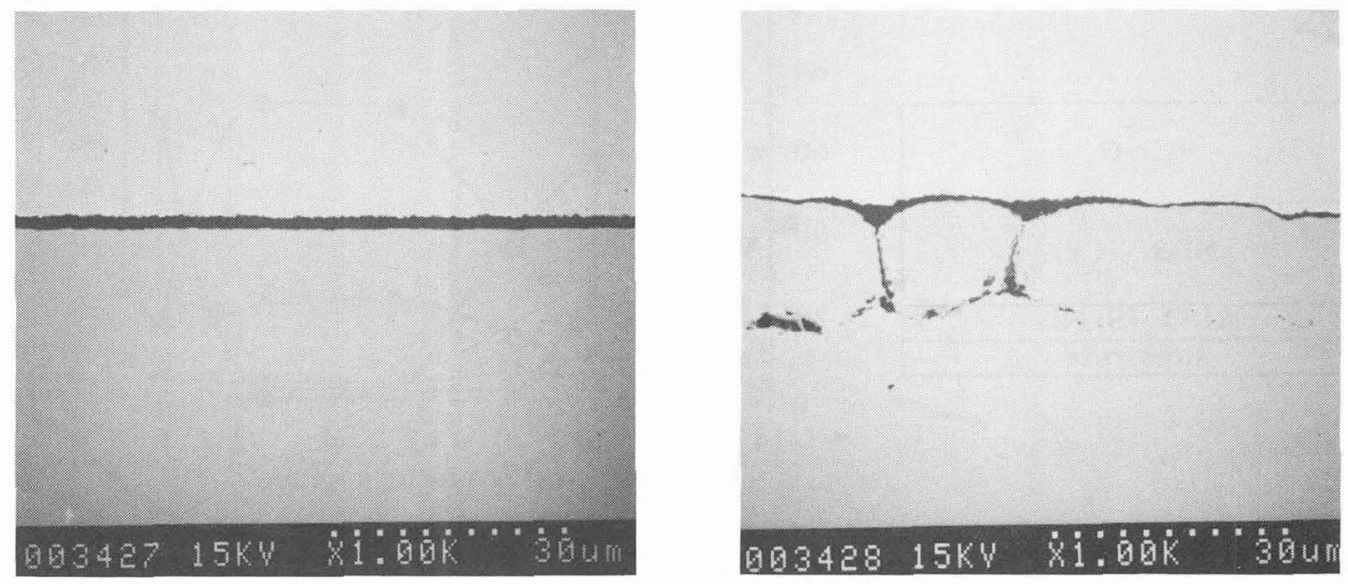

Figure 6 : cross sectional SEM micrographs of an uncoated $\mathrm{FeCrAl}$ (left) and a $\mathrm{FeCrAl/SiC} \mathrm{junction}$ (right) after ageing in air at $1420 \mathrm{~K}$ from 10 hours

Figure 7 illustrates the different phases which were found after two oxidation times. As for $\mathrm{NiCrAl}$ case, chromium migrates outward to give a thin chromium oxide film which is adjacent to an alumina phase beneath. $\mathrm{Al}_{2} \mathrm{O}_{3}$, even after 100 hours does not constitute a continuous layer. So, the presence of the coating (as previously completely reacted) changes the morphology and nature of the scale. On these results, chromium diffuses more rapidly than aluminium. The final sequence is more or less consistent with the general statement reported in literature on oxidation of metals and alloys, that is : the more in depth oxides are the more stable ones [14]. Moreover, all silicon which is in the deposit is combined with iron as $\alpha(\mathrm{Fe}, \mathrm{Si})$ solid solution in accordance with previous results. The concentration profiles on figure 7 (right) distinguish three zones and then the substrate. Here again, the silicon carbide based layer is transformed :

zone 1 : possibly spinels or mixed oxides of $\mathrm{Fe}, \mathrm{Cr}$

zone 2 : silicide layer

zone 3 : alloy strongly enriched in $\mathrm{Al}$ 


\begin{tabular}{|l|l|}
\hline \multicolumn{3}{|c|}{ Cr-O } \\
\hline Al-O & \\
\hline \multirow{2}{*}{ Fe-Si } \\
\hline Substrate \\
\hline
\end{tabular}

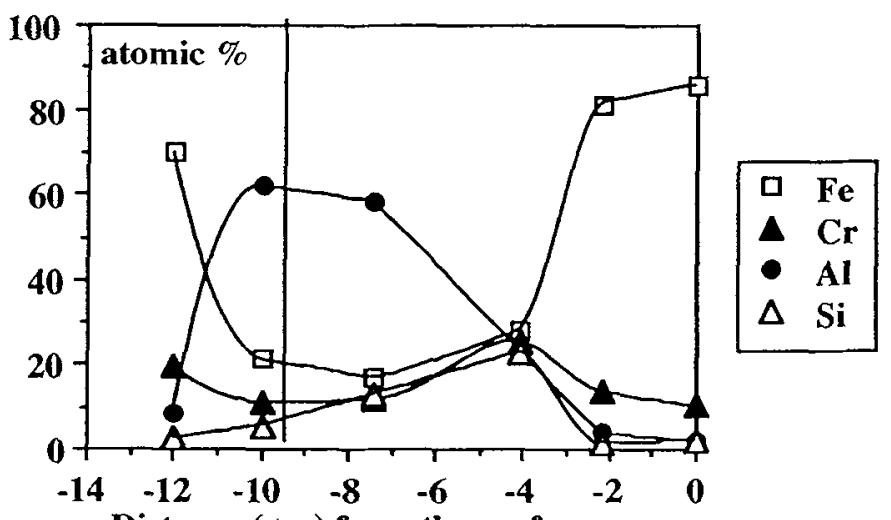

Distance $(\mu \mathrm{m})$ from the surface

Figure 7 : (left) scheme of an EDS mapping after long oxidation in air $(1273 \mathrm{~K}, 180 \mathrm{~h})$ - (right) crosssectional EDS profiles of a junction $\mathrm{FeCrAl} / \mathrm{SiC}(9.5 \mathrm{\mu m})$ after oxidation in air at $1420 \mathrm{~K}$ for 10 hours $(0$ : outer surface)

This comes from a similar process as described in the previous case. The smoother profile in silicon may be correlated to the lower reactivity between $\mathrm{Fe}$ and $\mathrm{SiC}$ in regards to nickel [6]. Here also to increase strongly the oxidation resistance of $\mathrm{FeCrAl}$ by a $\mathrm{SiC}$ based outer layer, a diffusion barrier will be needed. In a preliminary step, before the PACVD process, the substrate was oxidized in order to get a dense oxide layer $\left(1.5 \mu \mathrm{m} \mathrm{Al}_{2} \mathrm{O}_{3}\right)$ as shown on figure 5 . This bilayer is illustrated in figure 8 by cross-sectional concentration profiles. Oxygen in the coating is due to a small leak in the used device. After oxidating the $\mathrm{FeCrAl} / \mathrm{Al}_{2} \mathrm{O}_{3} / \mathrm{SiC}$ stack at $1273 \mathrm{~K}$ for 10 hours, the results are pertinent (figure $8 \mathrm{~b}$ ). There is no more interaction between the substrate and the silicon carbide based film. Moreover, silica is detected on the surface due to the oxidation of pure $\mathrm{SiC}$. In conclusion, in regards to these preliminary results alumina appears as an interesting diffusion barrier which needs more investigations to optimize a protection with a silicon carbide film.
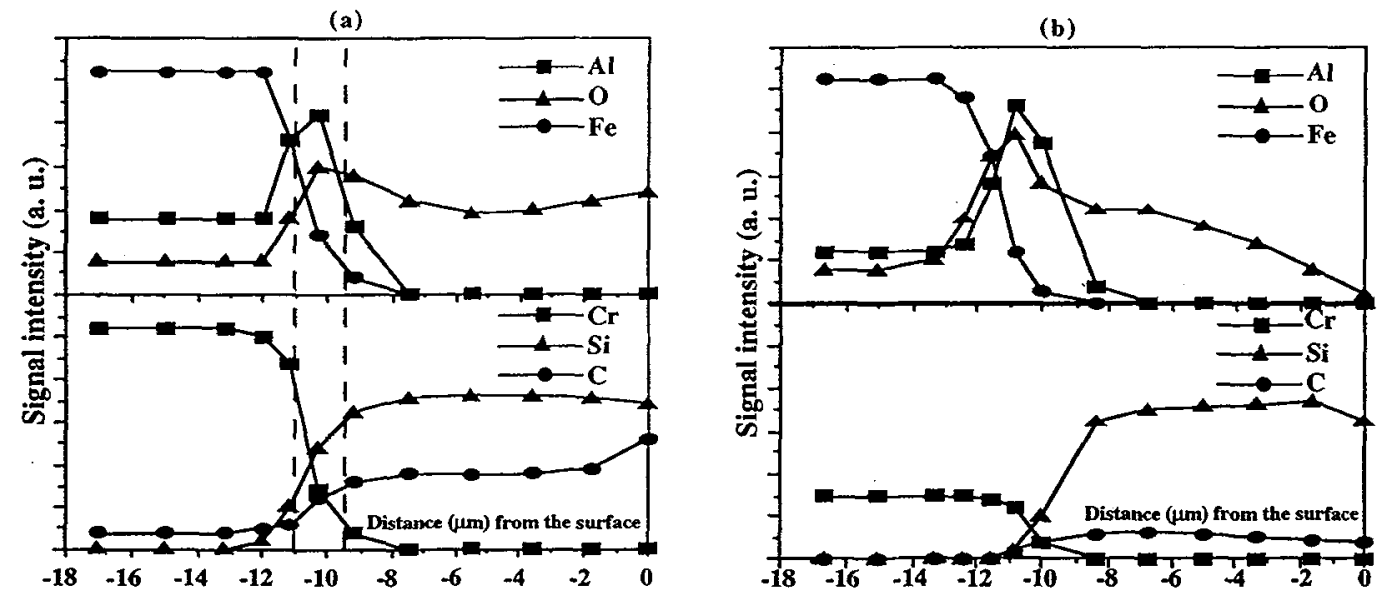

Figure 8: WDS concentration profiles (cross section) of a SiC coating on (a) FeCrAl oxidized (interlayer of $\left.\mathrm{Al}_{2} \mathrm{O}_{3}\right)$ and (b) of the same couple after oxidation at $1273 \mathrm{~K}$ for 10 hours (0: outer surface) 


\section{Conclusions}

By PACVD at around $700 \mathrm{~K}$, adherent $\mathrm{SiC}$ based films are obtained. An interaction layer counterbalancing the large thermal expansion mismatchs, is responsible for adherence. After extended oxidation tests by exposure in air $(1273 \mathrm{~K})$, the $10 \mu \mathrm{m}$ thick deposit is, in both cases, completely converted into silicides, but this strongly modifies the behavior against oxidation. For the NiCrAl case, the $\mathrm{Al}_{2} \mathrm{O}_{3}$ dendrites penetrating the substrate, and which are detrimental for some applications are suppressed. We can assume that $\mathrm{Si}$ suppress the intergranular diffusion of oxygen. So, the introduction of silicon offers some promise to increase the resistance of such alloys. In the FeCrAl case, the problem of oxidation is less important. Moreover, it is shown that intermediate $\mathrm{Al}_{2} \mathrm{O}_{3}$ layer is a barrier for interactions with silicon and then uses the stack $\mathrm{FeCrAl} / \mathrm{Al}_{2} \mathrm{O}_{3} / \mathrm{SiC}$ to temperatures largely above the deposition temperature.

\section{REFERENCES}

[1] F.Sibieude, J.Rodriguez and M.T. Clavaguera-Mora, Thin Solid Films; 204(1991)217-227.

[2] D.P.Stinton, T.M. Besmann and R.A. Lowden, Ceram. Bull.; 67, 2(1988)350-355.

[3] M.Lelogeais and M.Ducarroir, Surface and Coating Tech.; 48(1991)121-129.

[4] A.Inspektor,

Surface Science and Tech.; 33(1987)31-48.

[5] R.Avni and U.Carmi,

[6] R.Schieppers; .

Thesis; Eindhoven; (1990).

[7] M.Lelogeais and M.Ducarroir;

[8] M.Nathan and J.S.Ahearn; J.App.Phys.; 70, 2(1991)811-820.

[9] T.C.Chou and A.Jooshi;

J.Am.Ceram.Soc; 74, 6(1991)1364-1372.

[10] M.Backaus-Ricoult; J.de Phy.; Col.C1, Tome 51, (1990)C1-769.

[11] M.R.Jackson, R.L.Mehan, A.M.Davis and E.L.Hall; Met.Trans.A; 14A(1983)355-364.

[12] J.C.Viala, P.Fortier and J.Bouix; J.Mat.Sci.; 25(1990) 1842-1850.

[13] E.Cappelli, G.Giunta, A.Panetta and V.Adoncecchi; High performance ceramic films and coatings; Ed.P.Vicenzini; Elsevier; (1991)409427.

[14] P. Mazars;

Métaux, corrosion, industrie, $n^{\circ} 686$, octobre, $1982,321-338$ 